Vol. 4, No. 1, Juni 2020, hal. 39-47

ISSN 2598-3245 (Print), ISSN 2598-3288 (Online)

DOI: http://doi.org/10.31961/eltikom.v4i1.141

Tersedia online di http://eltikom.poliban.ac.id

\title{
RANCANG BANGUN GAME BIROKRASI PENYELENGGARAAN KEGIATAN KEMAHASISWAAN MENGGUNAKAN METODE FINITE STATE MACHINE
}

\author{
Anna Thasyia Puspita, Septi Andryana, dan Ratih Titi Komala Sari \\ Fakultas Teknologi Komunikasi dan Informatika, Universitas Nasional, Jakarta, Indonesia \\ e-mail: annathasyia@gmail.com, septi.andryana@civitas.unas.ac.id, ratih.titi@civitas.unas.ac.id
}

Diterima 11 Desember 2019 - Direvisi 28 Januari 2020 - Disetujui 30 Januari 2020

\begin{abstract}
Organization and student activities are inseparable. Lack of knowledge of organization members about the bureaucracy in organizing student affairs is caused by a lack of education before organizational registration. Based on the problems that have been described, a game is made about the bureaucracy in organizing student activities to become a learning medium for prospective members of the organization about the procedures for organizing student activities. From the results of testing the game using a questionnaire obtained an average percentage of $96.76 \%$ of users stating that the game is by its function, it can be said this game fulfills the initial purpose of making it into a learning medium to prospective members of the organization about the procedures for organizing student activities.
\end{abstract}

Keywords: finite state machine, game, organization.

\section{ABSTRAK}

Organisasi dan kegiatan kemahasiswaan adalah hal yang tidak dapat dipisahkan. Kurangnya pengetahuan anggota organisasi tentang birokrasi penyelenggaraan kemahasiswaan disebabkan oleh kurangnya edukasi sebelum pendaftaran organisasi. Berdasarkan permasalahan yang telah diuraikan, maka dibuat game tentang birokrasi penyelenggaraan kegiatan kemahasiswaan dengan tujuan menjadi media pembelajaran kepada calon anggota organisasi tentang prosedur penyelenggaraan kegiatan kemahasiswaan. Game ini dirancang menggunakan metode Finite State Machine dengan tujuan memberikan edukasi terhadap pengguna tentang proses penyelenggaraan kegiatan kemahasiwaan. Dari hasil pengujian game menggunakan skala likert didapat persentase rata - rata 96,76\% pengguna menyatakan bahwa game telah sesuai dengan fungsinya, maka dapat dikatakan game ini memenuhi tujuan awal pembuatannya yaitu menjadi media pembelajaran kepada calon anggota organisasi tentang prosedur penyelenggaraan kegiatan kemahasiswaan.

Kata Kunci: finite state machine, game, organisasi.

\section{PEndahuluan}

$\mathrm{P}$ ERKEMBANGAN teknologi informasi yang sangat pesat di era globalisasi saat ini telah memberikan manfaat dalam kemajuan di berbagai aspek kehidupan [1]. Teknologi juga dapat dijadikan sebagai media pembelajaran, salah satunya melalui teknologi game. Kebiasaan bermain game tak selalu membawa pengaruh negatif, namun juga memberi pengaruh positif yakni membuat kegiatan belajar dapat dilakukan dengan menyenangkan melalui media permainan [2].

Game edukasi adalah salah satu genre yang dapat dimainkan oleh semua kalangan, termasuk mahasiswa. Mahasiswa dalam kesehariannya belajar di perguruan tinggi tentu dihadapkan pada banyak kegiatan ekstrakulikuler termasuk organisasi kemahasiswaan [3]. Dalam hal ini banyak mahasiswa yang mendaftarkan diri menjadi anggota organisasi kemahasiswaan tanpa memahami terlebih dahulu apa yang akan mereka lakukan ketika terjun dalam organisasi [4]. Salah satu hal mendasar dalam organisasi yang sering tidak dipahami mahasiswa adalah tentang proses atau birokrasi penyelenggaraan kegiatan kemahasiswaan itu sendiri [5]. 


\section{Jurnal ELTIKOM : Jurnal Teknik Elektro, Teknologi Informasi dan Komputer}

Penelitian ini akan dirancang dengan menggunakan metode Finite State Machine (FSM) yang digunakan untuk proses perpindahan antar soal, sebab FSM terdiri dari rangkaian state yang mengarahkan pada soal selanjutnya dan tidak mengembalikan nilai untuk mengulang soal sebelumnya [6]. Konsep Forward Chaining serupa dengan FSM, namun perpindahan state tidak berurutan karena bergantung pada jenis input yang dipilih[7]. Penerapan Forward Chaining kurang sesuai sebab pada game yang dirancang dibutuhkan state yang berurutan, maka penerapan FSM pada game akan mengarahkan pengguna untuk fokus pada waktu yang diberikan pada setiap soalnya. Dari kesesuaian konsep pada metode FSM, maka peneliti tertarik untuk menerapkan metode FSM dalam game yang dirancang.

Berdasarkan penjabaran latar belakang masalah tersebut, maka dibuat rancangan permainan edukasi tentang prosedur penyelenggaraan kegiatan kemahasiswaan himpunan mahasiswa dan kampusnya bagi mahasiswa dan calon mahasiswa, juga bagi para alumni yang ingin mengenang masa-masa menjadi anggota organisasi ketika menjadi mahasiswa dengan tujuan menjadi media pembelajaran kepada calon anggota organisasi agar memahami prosedur penyelenggaraan kegiatan kemahasiswaan dikemudian hari.

\section{Metode Penelitian}

A. Kerangka Penelitian

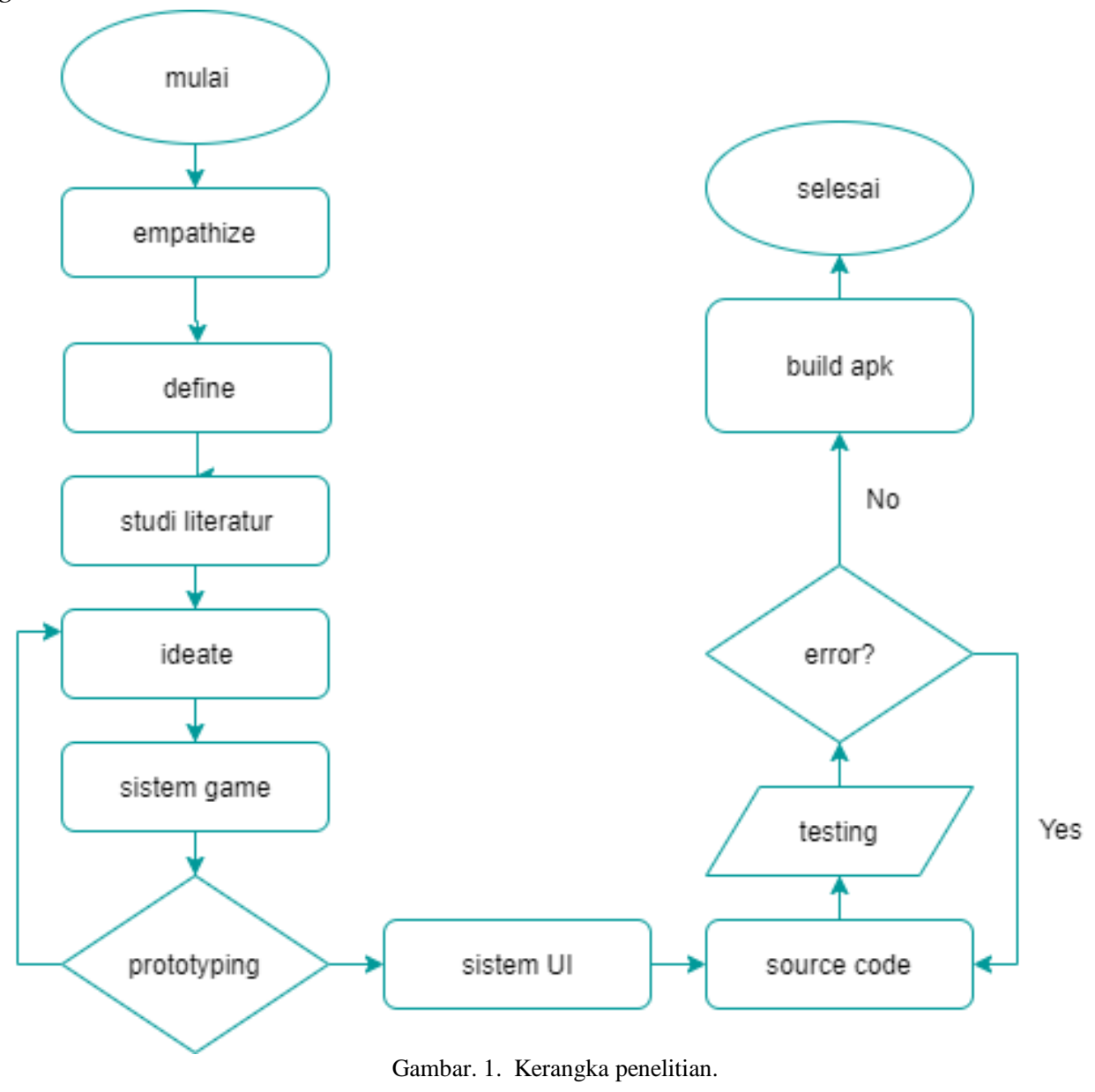

Flowchart kerangka penelitian menunjukkan garis besar pemikiran dalam penelitian yang dilakukan. Penelitian dimulai dengan melakukan observasi terhadap pengguna [8]. Tahap penelitian diawali dengan menyebarkan kuisioner kepada para anggota organisasi baik dari lingkup mahasiswa maupun pelajar. Hasil dari kuisioner tersebut kemudian digambarkan menjadi sebuah ide yang menjadi dasar dari aplikasi yang akan dibuat, kemudian mengumpulkan jurnal-jurnal terkait kemudian menggambarkan ide permainan lalu membentuk sistem permainan dilanjutkan dengan proses prototyping, membangun interface permainan, lalu menambahkan source code dalam permainan. Setelah semua selesai kemudian 


\section{Jurnal ELTIKOM : Jurnal Teknik Elektro, Teknologi Informasi dan Komputer}

melakukan pengujian kepada beberapa calon pengguna. Jika beberapa calon pengguna tersebut tidak menemukan kesulitan memahami alur permainan, baru kemudian dibangun aplikasi tersebut.

\section{B. Finite State Machine}

Finite State Machine (FSM) adalah serangkaian state yang menentukan pengambilan keputusan. Setiap pernyataan akan berpindah ke pernyataan lainnya jika mendapat masukkan dan memenuhi kondisi yang telah ditentukan sebelumnya [9]. Gambar 2 menunjukkan alur kerja pada finite state machine. Finite State Machine juga dikenal sebagai metodologi perancangan sistem kontrol yang menggambarkan tingkah laku atau prinsip kerja sistem dengan menggunakan indikator keadaan, kejadian dan aksi[10]. Dalam state machine sistem menempati satu keadaan atau halaman. Sistem akan berpindah menuju halaman lain ketika mendapatkan masukan berupa aksi tertentu [11]. Sistem akan tetap berada pada halaman yang sama sampai sistem menerima aksi tertentu [12]. Setiap halaman terhubung oleh transisi dan setiap transisi mengarah ke halaman lainnya. Transisi keadaan ini umumnya juga disertai oleh aksi yang dilakukan oleh sistem ketika menanggapi masukan yang terjadi.

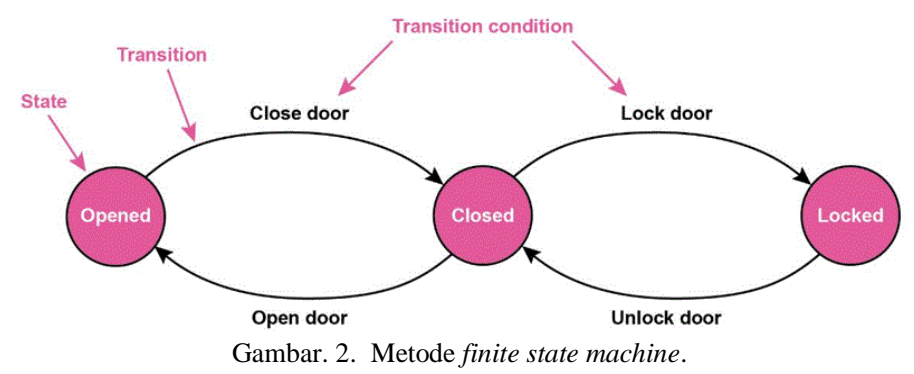

Dalam permainan ini terdapat beberapa level yang harus dimainkan, dimana dalam satu tugas terdapat beberapa tugas atau pertanyaan yang harus diselesaikan untuk melanjutkan ke level selanjutnya. Penerapan metode finite state machine disematkan dalam pengambilan keputusan didalam permainan ini untuk menyelesaikan semua tugas dan pertanyaan yang terdapat dalam tingkatan dalam permainan.

\section{Rancangan Permainan}

Pada bagian ini, metode Finite State Machine dikembangkan. Prosedur permainannya adalah sebagai berikut.

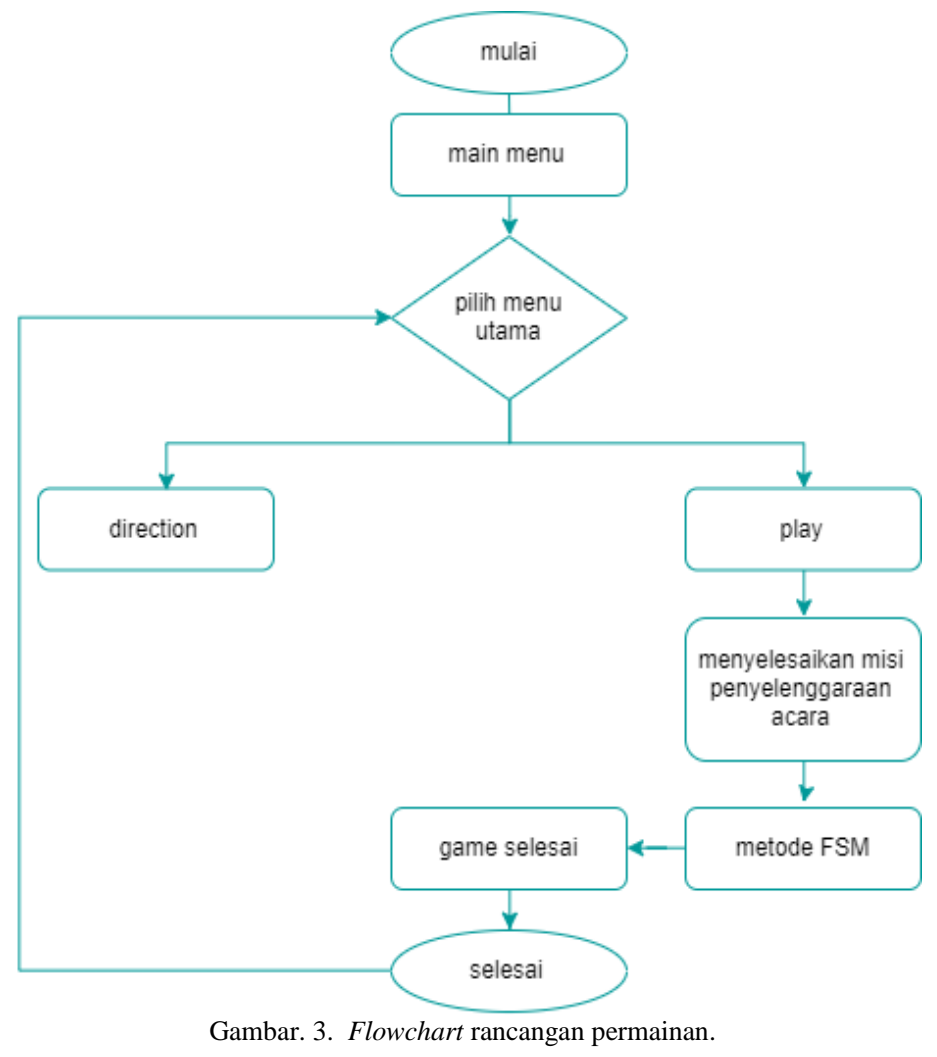




\section{Jurnal ELTIKOM : Jurnal Teknik Elektro, Teknologi Informasi dan Komputer}

Flowchart ini menjelaskan urutan prosedur yang ada didalam permainan. Pada saat game dijalankan maka pengguna akan berhadapan dengan halaman utama yang berisi menu play dan direction. Pilih mulai game untuk memulai permainan dan menyelesaikan misi untuk menyelenggarakan acara dengan mengikuti instruksi yang ada. Permainan ini akan berakhir jika semua tugas telah dikerjakan. Setelah itu pengguna akan melihat sebuah splash screen jika permainan selesai yang kemudian akan otomatis mengantarkan mereka ke menu utama.

\section{Construct 2}

Construct 2 merupakan sebuah game yang digunakan untuk membuat game khususnya dalam bentuk 2 dimensi dengan menggunakan bahasa dasar HTML5 [13]. Salah satu keunggulan Construct 2 antara lain Quick and Easy [14]. Layout editor mudah dimengerti karena tampilan yang muncul pada layar editor akan sama persis dengan tampilan yang muncul pada perangkat [15].

\section{E. Design Thinking}

Design thinking adalah metode yang digunakan untuk memecahkan suatu permasalahan yang kompleks. Tujuannya adalah untuk mencari solusi yang paling efektif dan efisien. Design thinking tidak membuat kita menghabiskan energi untuk membahas suatu masalah, melainkan fokus mencari solusi. Ada 5 tahapan dalam design thinking sebagai berikut.

\section{1) Empathize}

Dimana seorang developer berusaha memahami masalah dari sudut pandang pengguna. Dalam hal ini developer dapat melakukan wawancara langsung pada calon pengguna [16].

\section{2) Define}

Dari hasil wawancara, kini developer dapat mendefinisikan masalah yang ada dan mengumpulkan ide terkait pemecahan masalah yang ada dan menjadi dasar dari aplikasi yang akan dibuat.

\section{3) Ideate}

Dari banyak ide yang muncul pada proses define, pada tahap ini saatnya mengerucutkan ide menjadi satu kesimpulan yang menjadi solusi dari permasalahan.

\section{4) Prototype}

Pada tahap ini ide masuk dalam proses perancangan aplikasi uji coba.

\section{5) Testing}

Produk uji coba yang sudah dibuat kemudian diuji langsung oleh pengguna. Dari tahap ini akan didapatkan masukkan untuk melakukan perbaikan dari aplikasi yang telah ada.

\section{HASIL DAN PEMBAHASAN}

\section{A. Analisis Kebutuhan}

Penelitian ini menggunakan beberapa perangkat keras sesuai pada Tabel 1 dan perangkat lunak sesuai pada Tabel 2.

TABEL 1

SPESIFIKASI PERANGKAT KERAS.

\begin{tabular}{cc}
\multicolumn{2}{c}{ SPESIFIKASI PERANGKAT KERAS. } \\
\hline \hline PERANGKAT & SPESIFIKASI \\
\hline Sistem Operasi & Windows 10 64-bit \\
Prosesor & AMD Ryzen 5 2500U \\
VGA & AMD Radeon Vega 8 Graphics \\
SSD & 256 GB \\
RAM & $8 \mathrm{~GB}$ \\
\hline \hline
\end{tabular}

TABEL 2

SPESIFIKASI PERANGKAT LUNAK.

\begin{tabular}{cc}
\hline \hline PERANGKAT & FUNGSI \\
\hline Adobe XD & Untuk prototyping rancangan aplikasi \\
Adobe Illustrator CC 2017 & Untuk merancang assets permainan \\
Construct 2 & Untuk membangun dan mengatur layout game \\
Draw.io & Untuk pembuatan alur sistem \\
Adobe Phonegap & Untuk build aplikasi \\
\hline \hline
\end{tabular}




\section{Jurnal ELTIKOM : Jurnal Teknik Elektro, Teknologi Informasi dan Komputer}

B. Perancangan

Construct 2 adalah sebuah Game Engine yang digunakan untuk perancangan aplikasi. Sebelum merancang permainan terlebih dahulu harus memiliki assets 2D untuk dimasukkan ke dalam software dilanjutkan dengan proses pemberian animasi dan logic, kemuadian memasukkan game ke dalam android [16].

1) Membuat Prototype Design

Perancangan prorotype design menggunakan software Adobe XD untuk memberi gambaran awal bentuk dan interaksi dalam aplikasi.

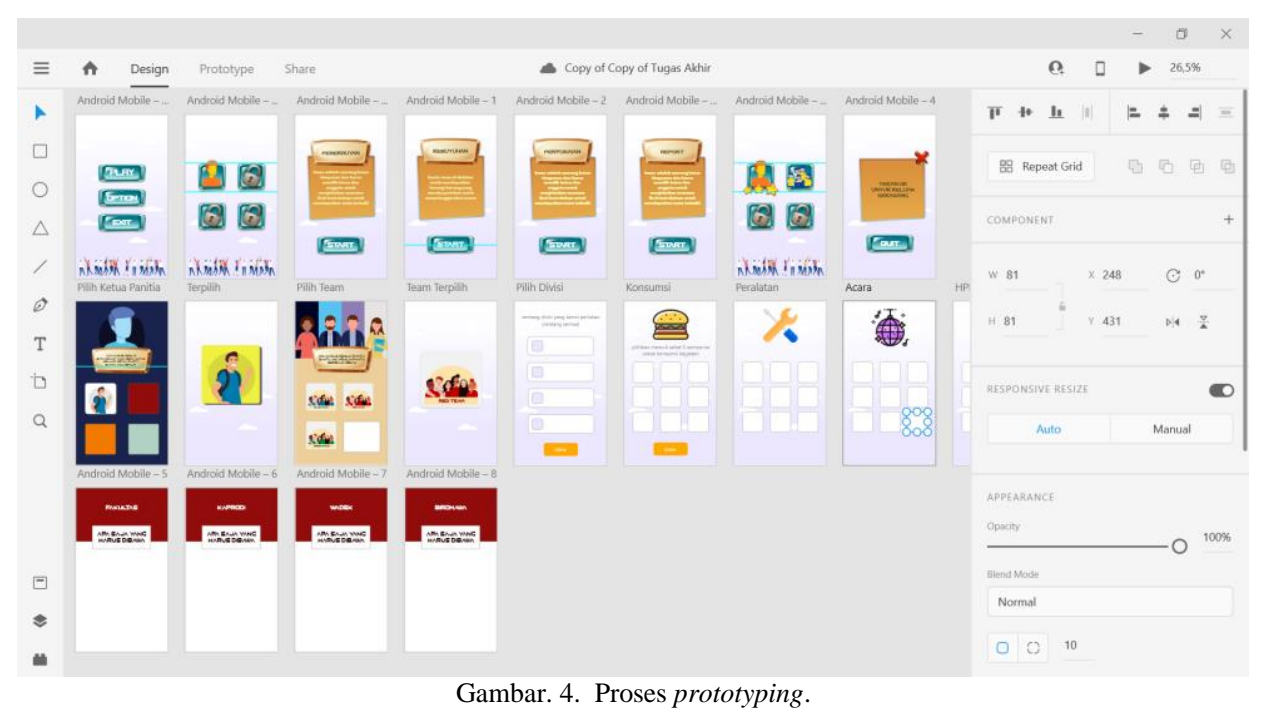

\section{2) Membuat Asset Permainan}

Pembuatan assets permainan menggunakan software Adobe Illlustrator untuk kemudian diimport ke Construct 2.

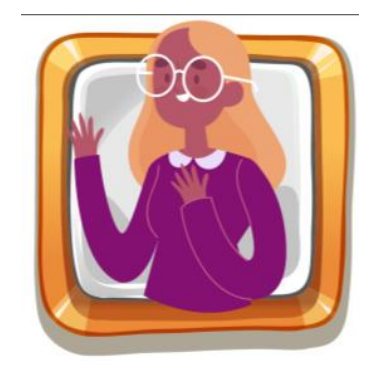

Gambar. 5. Proses design asset.

\section{3) Merancang UI Permainan}

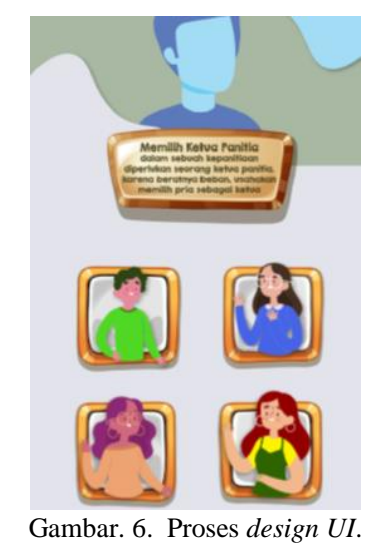




\section{Jurnal ELTIKOM : Jurnal Teknik Elektro, Teknologi Informasi dan Komputer}

4) Membuat Logic dan Animasi Game

Menambahkan proses logika dan animasi dalam game melalui Event Sheet pada tiap jendela tampilan.

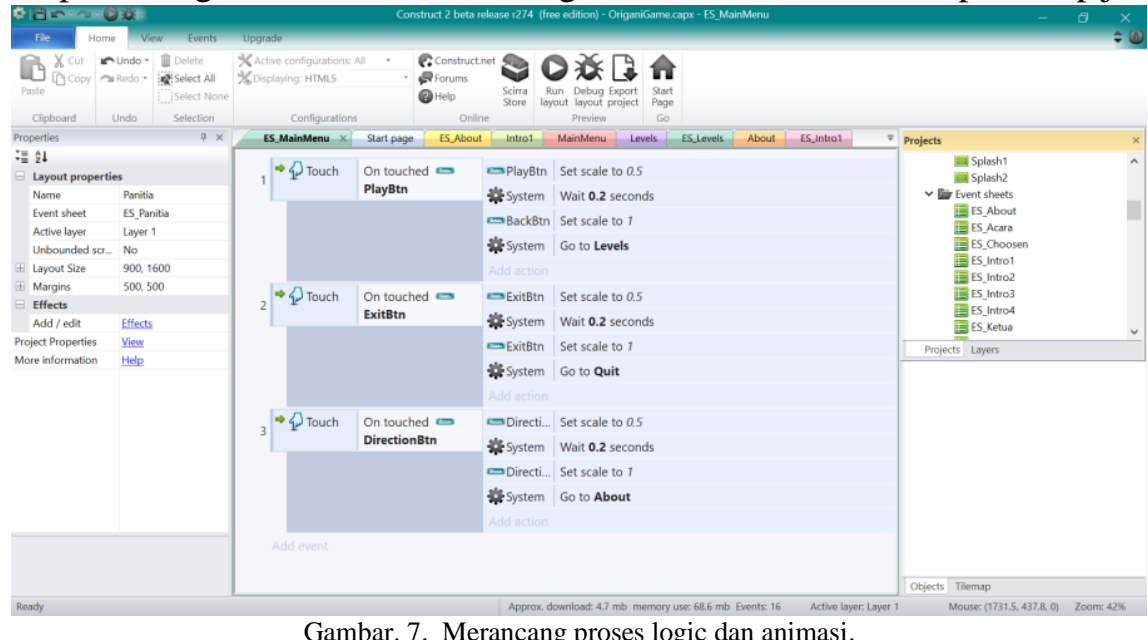

C. Tampilan Aplikasi

1) Tampilan Menu Utama

Ketika aplikasi dijalankan terdapat tampilan Main Menu yang berisi tombol Start dan Direction.

\section{TRAY}

\section{TRECTION}

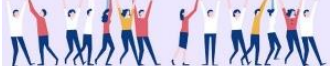

Gambar. 8. Tampilan menu utama

\section{2) Tampilan Menu Direction}

Ketika menekan tombol Direction pada menu utama akan muncul tampilan yang berisi petunjuk permainan.

\section{Petunjuk Permainon}

Pelunjuk Permainan

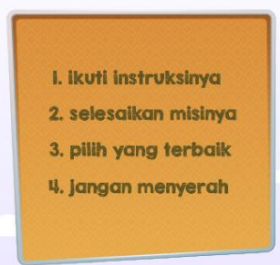

BACK

Gambar. 9. Tampilan menu Direction. 


\section{Jurnal ELTIKOM : Jurnal Teknik Elektro, Teknologi Informasi dan Komputer}

3) Tampilan Game

Saat menekan tombol Start, akan menampilkan UI level pertama dalam permainan seperti pada Gambar 6.

4) Tampilan Permainan Selesai

Ketika pengguna telah selesai melewati semua prosedur penyelenggaraan acara, akan tampil splash screen seperti gambar di bawah kemudian akan otomatis menuju halaman menu utama.

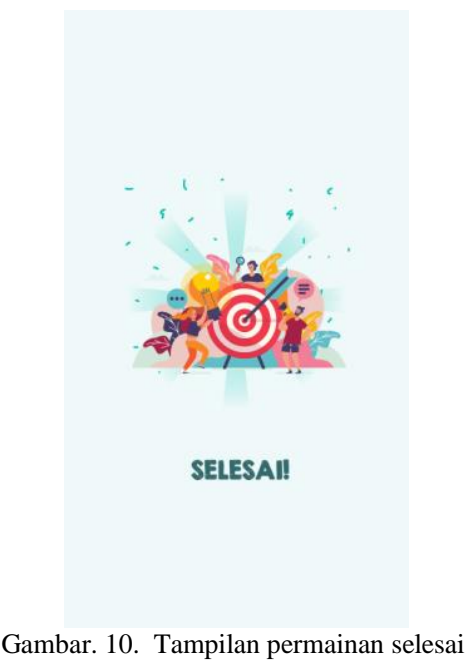

\section{Pengujian terhadap device}

Pengujian program dilakukan pada 5 perangkat smartphone dengan spesifikasi perangkat yang berbeda dan bersistem android. Pengujian dilakukan dengan menguji aplikasi pada kelima smartphone apakah dapat berjalan baik atau tidak.

TABEL 3

SPESIFIKASI SMARTPHONE YANG DIUJIKAN.

\begin{tabular}{ccccc}
\hline \hline \multirow{2}{*}{ PERANGKAT } & OPERATING SYSTEM & UKURAN LAYAR & RAM & CPU \\
& & & & \\
\hline 1 & v9.0 (Android Pie) & $1080 \times 2340$ pixel & $4 \mathrm{~GB}$ & Octa-core $1.7 \mathrm{GHz}$ \\
2 & v8.1 (Android Oreo) & $1520 \times 720$ pixels & $2 \mathrm{~GB}$ & Octa-core $1.8 \mathrm{GHz}$ \\
3 & v8.0 (Android Oreo) & $1480 \times 230$ pixels & $3 \mathrm{~GB}$ & Octa-core $1.6 \mathrm{GHz}$ \\
4 & v7.1.1 (Android Nougat) & $1080 \times 1920$ pixels & $3 \mathrm{~GB}$ & Quad-core $1.4 \mathrm{GHz}$ \\
5 & v5.1.1 (Android Lollipop) & $1280 \times 720$ pixels & $2 \mathrm{~GB}$ & Quad-core $1.3 \mathrm{GHz}$ \\
\hline \hline
\end{tabular}

\section{E. Pengujian game}

Tahap ini adalah tahap penerapan rancangan permainan ke dalam sebuah aplikasi yang dapat dijalankan pada platform android yang memenuhi spasifikasi permainan. Pengujian ini meliputi pengujian UI aplikasi, animasi, warna dan resolusi.

TABEL 4

HASIL PENGUJIAN GAME.

\begin{tabular}{|c|c|c|c|c|}
\hline \multirow{2}{*}{ PERANGKAT } & \multicolumn{4}{|c|}{ KRITERIA PENGUJIAN } \\
\hline & UI APLIKASI & ANIMASI & WARNA & RESOLUSI \\
\hline 1 & Berhasil & Berhasil & Berhasil & Berhasil \\
\hline 2 & Berhasil & Berhasil & Berhasil & Berhasil \\
\hline 3 & Berhasil & Berhasil & Berhasil & Berhasil \\
\hline 4 & Berhasil & Berhasil & Berhasil & Berhasil \\
\hline 5 & Berhasil & Berhasil & Berhasil & Berhasil \\
\hline
\end{tabular}

Pengujian game dilakukan pada lima smartphone android dan didapatkan grafik UI aplikasi, animasi, warna dan resolusi dapat berjalan dengan sesuai dengan tampilan yang diharapkan. Dilakukan pengujian menggunakan kuisioner yang didapat dari 50 responden, digunakan pengujian menggunakan skala likert yang ditampilkan pada Tabel 5. 


\section{Jurnal ELTIKOM : Jurnal Teknik Elektro, Teknologi Informasi dan Komputer}

TABEL 5

Hasil PENGUJiAn SKala LiKeRT.

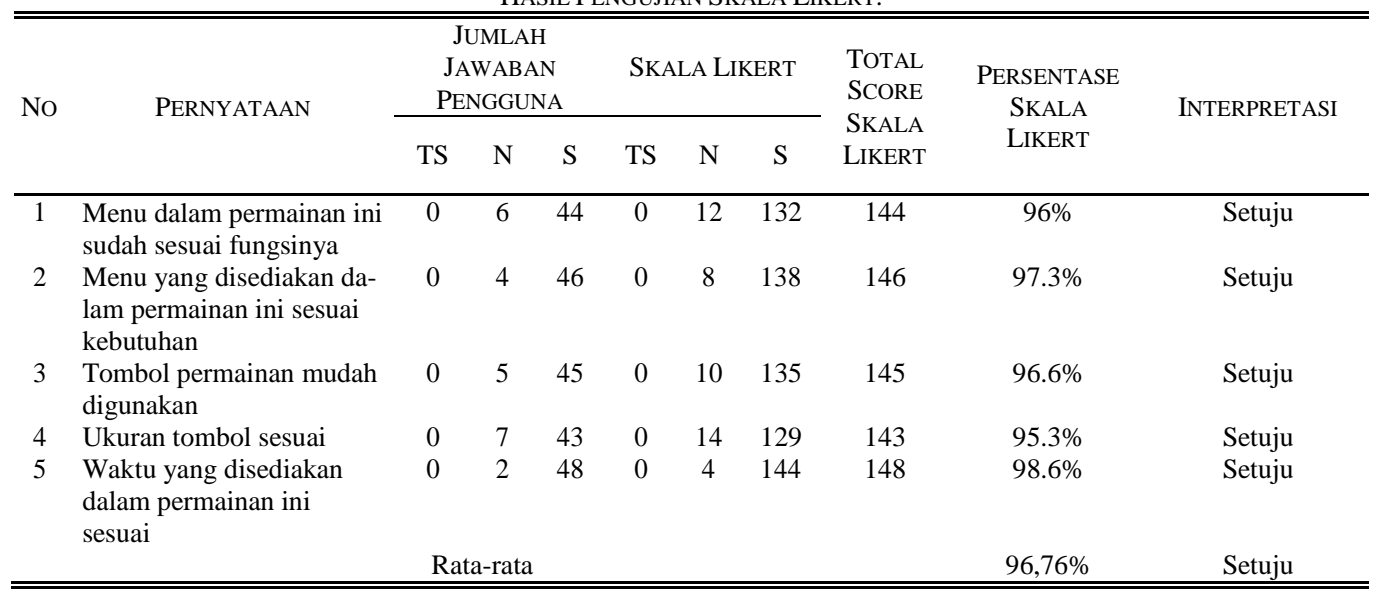

Tabel 5 merupakan hasil dari sebaran kuisioner yang berisikan pengalaman 20 pengguna (koresponden) dalam menavigasikan permainan yang dirancang. Pada kuesioner diberikan 5 pernyataan, jawaban dari pengguna kemudian diklasifikasikan menjadi Tabel 6.

\begin{tabular}{ccc} 
& \multicolumn{2}{c}{ TABEl 6 } \\
\multicolumn{3}{c}{ BobOt Nilai. } \\
\hline \hline NILAI & Bobot & Keterangan \\
& & \\
\hline TS & 1 & Tidak Setuju \\
N & 2 & Netral \\
S & 3 & Setuju \\
\hline \hline
\end{tabular}

Sebagai contoh pada pernyataan pertama, 6 pengguna menjawab netral dan 44 pengguna menjawab setuju. Pernyataan kedua 4 pengguna menjawab netral dan 46 pengguna menjawab setuju, dan seterusnya.

Skala Likert didapat dari perhitungan berikut:

$$
S L=J u m l a h \text { Jawaban User } \times \text { Bobot Jawaban. }
$$

Maka hasil jawaban responden pada pernyataan pertama adalah yang menjawab setuju (3) adalah $44 \mathrm{x}$ $3=132$. Responden menjawab netral (2) adalah $6 \times 2=12$. Responden menjawab tidak setuju (1) adalah $0 \times 1=0$. Maka total score yang didapat adalah $132+12+0=144$.

TABEL 7

PERSENTASE NILAI SKala LiKERTI.

\begin{tabular}{cl}
\multicolumn{2}{c}{ PERSENTASE NILAI SKALA LIKERTI. } \\
\hline PERSENTASE RATA - RATA & \multicolumn{1}{c}{ NILAI } \\
\hline $0 \%-33,99 \%$ & Tidak Setuju \\
$34 \%-67,99 \%$ & Netral \\
$68 \%-100 \%$ & Setuju \\
\hline \hline
\end{tabular}

Tabel 7 berisi persentase nilai. Untuk mendapat hasil presentase skala likert dan interpretasi, perlu diketahui skor tertinggi (X) dan skor terendah (Y).

$$
\begin{aligned}
& X=\text { bobot terting gi } \times \text { jumlah responden } . \\
& Y=\text { bobot terendah } \times \text { jumlah } r \text { esponden } .
\end{aligned}
$$

Maka nilai $X$ adalah $3 \times 20=150$. Nilai $Y$ adalah $1 \times 20=20$. Rumus index $\%$ nilai likert dapat dilihat 


\section{Jurnal ELTIKOM : Jurnal Teknik Elektro, Teknologi Informasi dan Komputer}

pada Persamaan 4.

$$
\text { Likert } \%=\frac{\text { Total Score }}{X} \times 100 \%
$$

Dari total score skala likert pada pernyataan pertama yaitu 144, maka persentase likert adalah (144/150) $\times 100 \%=96 \%$. Berdasarkan tabel persentase nilai, maka nilai $96 \%$ masuk dalam kategori SETUJU. Proses hitung tersebut dilakukan kepada kelima pernyataan, lalu hasil persentase nilai kelima pernyataan tersebut dirata-ratakan.Berdasarkan total dari hasil kuisioner tersebut didapat persentase rata - rata $96,76 \%$ yang menyatakan fungsi, menu, tombol navigasi dan waktu telah sesuai.

\section{KESIMPULAN}

Berdasarkan hasil perancangan game "Badan Event Mahasiswa" sebagai edukasi pengetahuan birokrasi penyelenggaraan kegiatan kemahasiswaan, dapat disimpukan bahwa hasil pengujian game menggunakan kuisioner didapat persentase rata - rata 96,76\% pengguna menyatakan bahwa game telah sesuai dengan fungsinya, maka dapat dikatakan game ini memenuhi tujuan awal pembuatannya yaitu menjadi media pembelajaran kepada calon anggota organisasi tentang prosedur penyelenggaraan kegiatan kemahasiswaan. Dari hasil game yang dibangun, didapatkan implikasi terkait bagaimana suatu kegiatan khususnya dalam kegiatan kemahasiswaan itu berjalan, sehingga mahasiswa dapat lebih memahami alur penyelenggaraan suatu kegiatan. Dalam bidang lain, perancangan game ini dapat digunakan sebagai gambaran dari cara berpikir untuk menentukan prosedur penyelenggaraan kegiatan diluar kemahasiswaan. Perancangan game ini menggunakan software Construct 2, Adobe Illustrator, Adobe Phonegap dan Adobe XD. Game ini berjalan dengan spesifikasi minimal OS Android Lollipop 5.1.1 dan RAM 2GB.

Berdasarkan penelitian ini, peneliti menyarankan untuk menambahkan variasi prosedur yang dibangun supaya lebih banyak contoh prosedur penyelenggaraan kegiatan.

\section{DAFTAR PUSTAKA}

[1] M. B. Nendya, S. Gandang, and R. G. Santosa, "Pemetaan Perilaku Non-Playable Character Pada Permainan Berbasis Role Playing Game Menggunakan Metode Finite State Machine,” J. Animat. Games Stud., vol. 1, no. 2, pp. 185-202, 2015.

[2] H. Haryanto, "Reward Dinamis dalam Skenario Adaptif Menggunakan Metode Finite State Machine pada Game Edukasi," J. Appl. Intell. Syst., vol. 1, no. 2, pp. 144-153, 2016.

[3] H. Haryanto, S. Novianto, and U. Rosyidah, "Model Skenario Adaptif Berbasis Finite State Machine Pada Game Pendidikan," Techno.COM, vol. 13, no. 2, pp. 91-98, 2014.

[4] Septa and A. Saifudin, "Penerapan Algoritma Finite State Machine pada Game Horror 3D untuk Melestarikan Budaya Tradisional Bangsa Berbasis Android," J. Inform. Univ. Pamulang, vol. 4, no. 1, p. 23, 2019.

[5] S. Rostianingsih, G. S. Budhi, and H. K. Wijaya, "Game Simulasi Finite State Machine Untuk Pertanian dan Peternakan," Surabaya, 2013.

[6] E. Yulsilviana and H. Ekawati, "Penerapan Metode Finite State Machine (FSM) Pada Game Agent Legenda Anak Borneo," SEBATIK, vol. 23, no. 1, pp. 116-123, 2019.

[7] Y. S. Putra, M. A. Muslim, and A. Naba, "Game Chicken Roll Dengan Menggunakan Metode Forward Chaining,"J. EECCIS, vol. 7, no. 1 , pp 41-46, 2019.

[8] D. S. Hormansyah, A. R. T. H. Ririd, and D. T. Pribadi, "Implementasi FSM (Finite State Machine) Pada Game Perjuangan Pangeran Diponegoro," J. Inform. Polinema, vol. 4, no. 4, p. 290, 2018.

[9] R. Dillon, HTML5 Game Development from the Ground Up with Construct 2, 1st ed. Boca Raton: CRC Press, 2014.

[10] P. Moreno-ger, D. Burgos, I. Martínez-ortiz, J. Luis, and B. Fernández-manjón, "Computers in Human Behavior Educational game design for online education," vol. 24, pp. 2530-2540.

[11] A. Muhson, "Pengembangan Media Pembelajaran Berbasis Teknologi Informasi," J. Pendidik. Akunt. Indones., vol. 8, no. 2, 2010.

[12] J. Youth, "Using a Role-Play Simulation Game to Promote Systems Thinking," J. Contin. Educ. Nurs., vol. 49, no. 1, pp. 10-11, 2018.

[13] M. F. Rahadian, A. Suyatno, and S. Maharani, "Penerapan Metode Finite State Machine Pada Game The Relationship," J. Inform. Mulawarman, vol. 11, no. 1, pp. 14-22, 2016.

[14] M. Adiwijaya, K. I. S, and Y. Christyono, "Perancangan Game Edukasi Platform Belajar Matematika Berbasis Android Menggunakan Construct 2," TRANSIENT, vol. 4, no. 1, pp. 128-133, 2015.

[15] N. I. Widiastuti and I. Setiawan, “Membangun Game Edukasi Sejarah Walisongo,” J. Ilm. Komput. dan Inform., vol. 1, no. 2, pp. 41-48, 2012.

[16] H. F. Ramadhan, S. H. Sitorus, and S. Rahmayuda, "Game Edukasi Pengenalan Budaya dan Wisata Kalimantan Barat Menggunakan Metdoe Finite State Machine Berbasis Android,” J. Komput. dan Apl., vol. 07, no. 1, pp. 108-119, 2019. 